\title{
WHEELCHAIR EXERCISE: A REVIEW
}

\author{
By Thomas E. Dreisinger, Ph.D. ${ }^{1}$ and Ben R. Londeree, Ed.D. ${ }^{2}$ \\ ${ }^{1}$ Department of Physical Medicine and Rehabilitation, University of Missouri Health \\ Sciences Center, ${ }^{2}$ Department of Health and Physical Education, University of Missouri, \\ Columbia, Missouri, U.S.A.
}

\begin{abstract}
Not much is known concerning the physiological performance capabilities of wheelchair confined populations. Further, the instrumentation to collect physiological data has not been available until recently. It is in the area of work capacity measurement of the handicapped that the arm ergometer is of greatest interest (particularly for those who have a functional loss of one or both legs).

In recent years, there has been an attempt to develop instrumentation and investigate some of the physiological issues surrounding quantified exercise in wheelchair confined populations.

The intent of this review is to provide the reader with an overview of the state of the art in wheelchair and wheelchair ergometric cardiorespiratory performance.
\end{abstract}

Key words: Wheelchair exercise; Ergometric cardiorespiratory performance.

In recent years there has been an increased interest in the metabolic energy expenditure of exercise in those confined to the wheelchair. The literature related to this area has been scattered in a variety of journals. The purpose of this review is to provide the reader with a central core of literature related to this fertile area of research.

Exercise stress tests provide valuable information concerning relative fitness levels (Astrand \& Rodahl, 1977). At present, most test protocols focus on the large muscles of the leg (Balke \& Ware, 1959; Fox et al., 1973). Viable exercise alternatives for the handicapped is one of the most neglected areas of exercise physiology. Since little is known concerning the physical capacities and exercise limits of any of the handicapped populations and since those confined to wheelchairs are becoming more and more visible in the realm of physical activity, there is a growing and vital need on the part of both the practitioner and the clinician for reliable exercise alternatives when faced with a situation involving a handicapped person. However, studies providing physiological data concerning this population are relatively rare and incomplete in the literature. A major reason for this has been the lack of instrumentation which could provide reliable physiological data.

An ergometer is an instrument used in the determination (measurement) of work. For the exercise physiologist, this is usually an instrument which measures active work done on some stationary piece of equipment. Many different methods for performing work have been devised; however, those most frequently used in physiological studies have involved bicycles, arm pedals (cranks), steps and treadmills. Several ergometric devices have been developed, and studies have examined the metabolic effects of propelling a wheelchair (Brouha \& Krobath, I967; Voigt \& Bahn, 1969; Brattgard et al., 1970).

It should be noted that these published studies, with the exception of very recent work, for the most part failed to report raw data, statistical methodology and statistical data (e.g., mean, standard deviation and statistical significance). 
The amount of available data related to wheelchair ergometry is limited; therefore, a comprehensive review of the literature will be presented in the following areas:

(a) Freewheeling Wheelchair Energy Costs

(b) Stationary Wheelchair Ergometry (Instrumentation and Energy Costs)

(c) Wheelchair Training

\section{(a) Freewheeling Wheelchair Energy Costs}

The first appearance in the literature regarding the cost of wheelchair ambulation was in the early I950s. Gordon (1952) was concerned about activity prescription for patients with pulmonary tuberculosis. He reported data in terms of the percentage exceeding basal conditions (see Table I).

Gordon later reported (1958) the energy cost of different activities in health and disease (e.g., walking, writing and reading). He included the energy costs of activities for ambulation via 'swing through gait' and wheelchair wheeling. In this study, three healthy subjects operated wheelchairs at a speed of $\mathrm{I} \cdot 2$ miles per hour. It was reported that the energy expenditure '. . . was $2.4 \mathrm{Cal}$., just about light work, industrially speaking'. The author noted that few data were available relative to ambulation of the handicapped.

Peizer, Wright and Freiberger (1964) examined several bioengineering methods of wheelchair evaluation. They studied three male tetraplegic subjects who were wheeling on a hard level surface. It was reported that '. . . wheelchair propulsion between $\mathrm{I} \cdot 2$ and $3.5 \mathrm{mph}$ used less energy than normal walking and substantially lower than above-knee amputee locomotion'. The metabolic energy expenditure for wheelchair propulsion is shown in Table II. Similar findings were reported by Engle and Hildebrandt (1973). These investigators indicated that '. . . energy expended in propelling a standard wheelchair at varying speeds is far less than that expended by a healthy subject during walking . . ' These data, however, do not agree with Glaser et al. (1975), who reported that operation of a manual wheelchair and walking at the same speed require a similar energy expenditure (see Fig. I). All these investigators did agree, however, that wheelchair wheeling does elicit greater cardiorespiratory stress to the system than walking. This

\section{TABLE I}

Per cent increase of energy cost of activities over basal

\begin{tabular}{ccc}
\hline Subject & Showering & $\begin{array}{c}\text { Self-Propulsion } \\
\text { in Wheelchair }\end{array}$ \\
$\mathrm{I}^{\star}$ & 242 & $\mathrm{I} 38$ \\
$2^{\star \star}$ & $30 \mathrm{I}$ & $\mathrm{I} 37$ \\
$3^{\star \star}$ & 377 & $\mathrm{I} 34$ \\
\hline$\star$ Patient & \\
$\star \star$ Normal Subjects &
\end{tabular}

Source: E. E. Gordon, 'Energy Costs of Various Physical Activities in Relation to Pulmonary Tuberculosis,' Archives of Physical Medicine (I952), 33, 20I-290.

Permission has been received from Archives of Physical Medicine and Rehabilitation for the use of this Table. 
TABLE II

\begin{tabular}{ccc}
\hline $\mathrm{Mph}$ & $\mathrm{Kcal} / \mathrm{min}$ & $=\mathrm{LO}_{2} / \mathrm{min}$ (estimated) \\
\hline $\mathrm{I} \cdot 2$ & $\mathrm{I} \cdot 2$ & 0.240 \\
$2 \cdot 7$ & 2.0 & 0.400 \\
$2 \cdot 9$ & $2 \cdot 7$ & 0.540 \\
$3 \cdot 2$ & $2 \cdot 8$ & 0.560 \\
3.4 & 2.9 & 0.580
\end{tabular}

Source: E. Peizer, D. Wright, and H. Freiberger, 'Bioengineering Methods of Wheelchair Evaluation', Bulletin of Prosthetics Research (I964) 10, 77-100.

was reflected in the greater heart rates for a given speed with wheelchair exercise compared to walking.

Wolfe et al. (I977) examined the energy cost of 'free' wheeling over carpeted and concrete surfaces with wheelchairs equipped with pneumatic tyres versus those equipped with hard rubber tyres. A total of 50 volunteers participated in this study. Twenty-five subjects (2I men and four women) had had no previous experience with wheelchair operation. Of the remaining 25 volunteers, ten were disabled subjects assessed as being in a state of general deconditioning due to long hospitalisation bedrest, and I 5 were paraplegic subjects normally accustomed to a wheelchair. The physiological variables observed were: (I) heart rate; (2) respiratory rate; and (3) oxygen uptake. All subjects completed a minimum of four trials (carpeting/pneumatic tyres, carpeting/hard rubber tyres, concrete/pneumatic tyres, concrete/hard rubber tyres). Subjects were allowed to travel at what they found to be a comfortable pace on each surface. Lack of workload standardisation made it difficult to compare data, since the amount of work performed was neither predetermined nor quantified in any way. It was noted that subjects travelled at significantly slower rates on the softer surface than on the harder surface. Since there was no reported attempt to encourage specific workloads, it was difficult to interpret the meaning of this information. No statistically significant differences

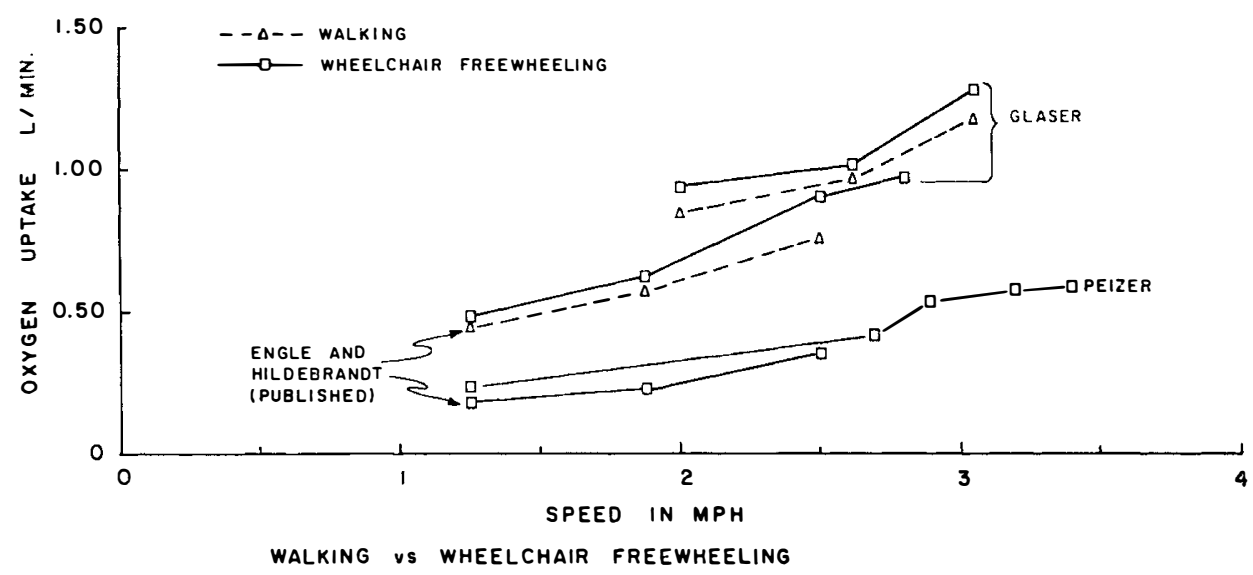

FIG. I 
were reported between the results obtained from using pneumatic tyres and those obtained from using hard rubber tyres. The authors did note, as previous arm and leg studies had shown (Astrand et al., 1965; Bevegard et al., 1966), that as work increased so did oxygen consumption and heart rate.

\section{(b) Stationary Wheelchair Ergometry (Instrumentation and Energy Costs)}

Instrumentation has been a major problem in measuring wheelchair work. The question of how to collect physiological data seemed burdensome and prohibitive. Several investigators attempted to develop stationary instruments which could provide physiological data relative to wheelchair work. Devices included: (I) platforms with bearings upon which a wheelchair was mounted (Brouha \& Krobath, I967; Brauer, I972; (2) treadmills upon which a wheelchair was mounted (Hildebrandt et al., I970); (3) stationary wheelchairs that were linked to bicycle ergometer flywheels (Brattgard et al., 1970); and (4) stationary wheelchair assembly with external flywheel compensation for body weight (Dreisinger, I980).

The first investigators to attack the problem of stationary wheelchair ergometric work were Brouha and Krobath (1967). They built a special platform with two pairs of rollers (mounted on precision bearings to eliminate friction), assembled in a manner that allowed chair wheels to rest easily on them. The system was designed to provide a stationary measuring device for observing different physiological exercise variables such as heart rate, cardiac cost and respiratory reactions (i.e., flow and temperature readings). Ventilation cost was expressed in terms of respiration rate and volume; mechanical work was measured in $\mathrm{kgm} / \mathrm{min}$. The authors reported that three experiments were performed. In the first, the subject was asked to cover a constant distance of 100 metres at his own pace; in the second, the subject worked for 3 minutes at his own pace; in the third, the subject was requested to perform a fixed number of strokes at a pre-set rate and was timed with a metronome. The authors reported, in a general manner, that heart rate, mechanical work performed and physiological effort measured as cardiac cost, increased proportionately as workload increased. They reported some sample data and indicated more complete data would be included in subsequent publications. So far as we know, these publications never appeared in the literature.

Stoboy et al. (I97I) used a wheelchair ergometer after the model of Brouha and Krobath (1967) to examine energy expenditure during wheelchair propulsion. Fifteen healthy, able-bodied, untrained male subjects, ranging in age from $\mathrm{I} 8$ to 30 years, were studied. These investigators attempted to correlate the ergometer work with that of normal free-wheeling. Five minutes of exercise on the ergometer at a stroke rate of 18 strokes per minute resulted in a distance covered of 52 metres. The free-wheelers operated at a 'conventional' speed and travelled an average distance of 250 metres in a 5-minute time period. Wheelchair work was compared to that of an arm pedal ergometer. Wheelchair workloads (both ergometer and free-wheeling) were then estimated by matching performance curves for heart rate and oxygen consumption to those of the arm pedal ergometer (see Fig. 2). This information was derived from data collected on the arm crank ergometer. The workloads presented during the free-wheeling and platform ergometric tests were superimposed on the arm crank regression slopes. It was the opinion of these investigators that the platform provided a viable means for the evaluation of physiological work bouts. The shortcoming of this system was that no accommodation was made for the effects of translational inertia that occurs during normal wheelchair operation. 


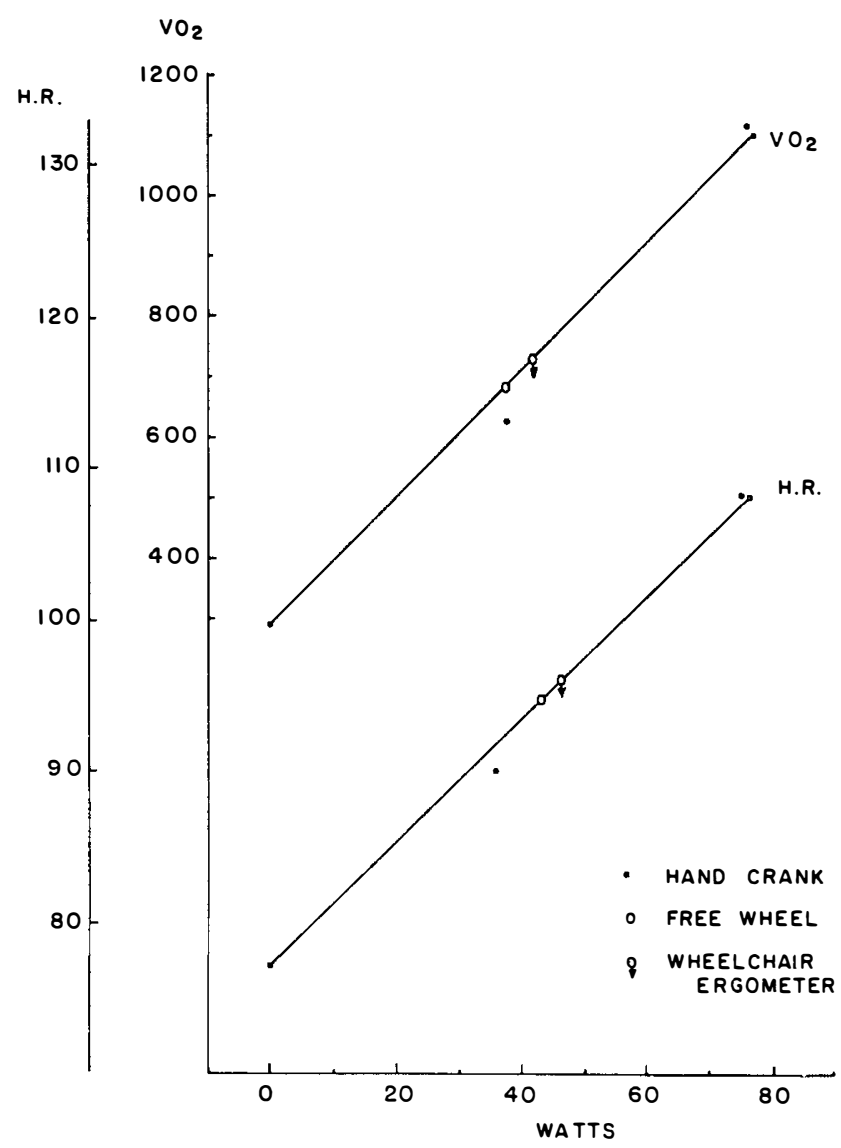

FIG. 2

Two German investigators (Voigt \& Bahn, 1969) approached the problem of instrumentation in another way. Their purpose was to investigate the energy cost of propelling a wheelchair up an incline. They mounted a wheelchair on a treadmill. It was their opinion that '. . . knowledge of the dimensions of this burden and its effect upon the circulation can be necessary for the successful rehabilitation ...' of handicapped individuals. Their subjects consisted of 29 pupils (I 7 girls and 12 boys) enrolled at their Centre. The experiment was conducted at $2^{\circ}$ and speeds of $\mathrm{I}, 2,3$ and $4 \mathrm{~km} / \mathrm{hr}$. Workloads corresponding to the treadmill speeds of I, 2, 3 and $4 \mathrm{~km} / \mathrm{hr}$ were approximately I I, 22, 33 and 44 watts, respectively $(67,135,202$ and $268 \mathrm{kpm} / \mathrm{min})$. The investigators presented their data in two groups: handicapped, and handicapped with additional defects (shoulder girdle involvement) (see Fig. 3). The results of their investigation showed metabolic rate increased with the increased workload. Oxygen and caloric consumption were correlated closely to the work performed. Heart rate also showed a close correlation with performance until workloads which caused muscular fatigue were reached. The investigators compared their data with those obtained from work with able-bodied subjects and found the same relationships existed as with the handicapped populations when similar muscle groups were exercised. Several of 


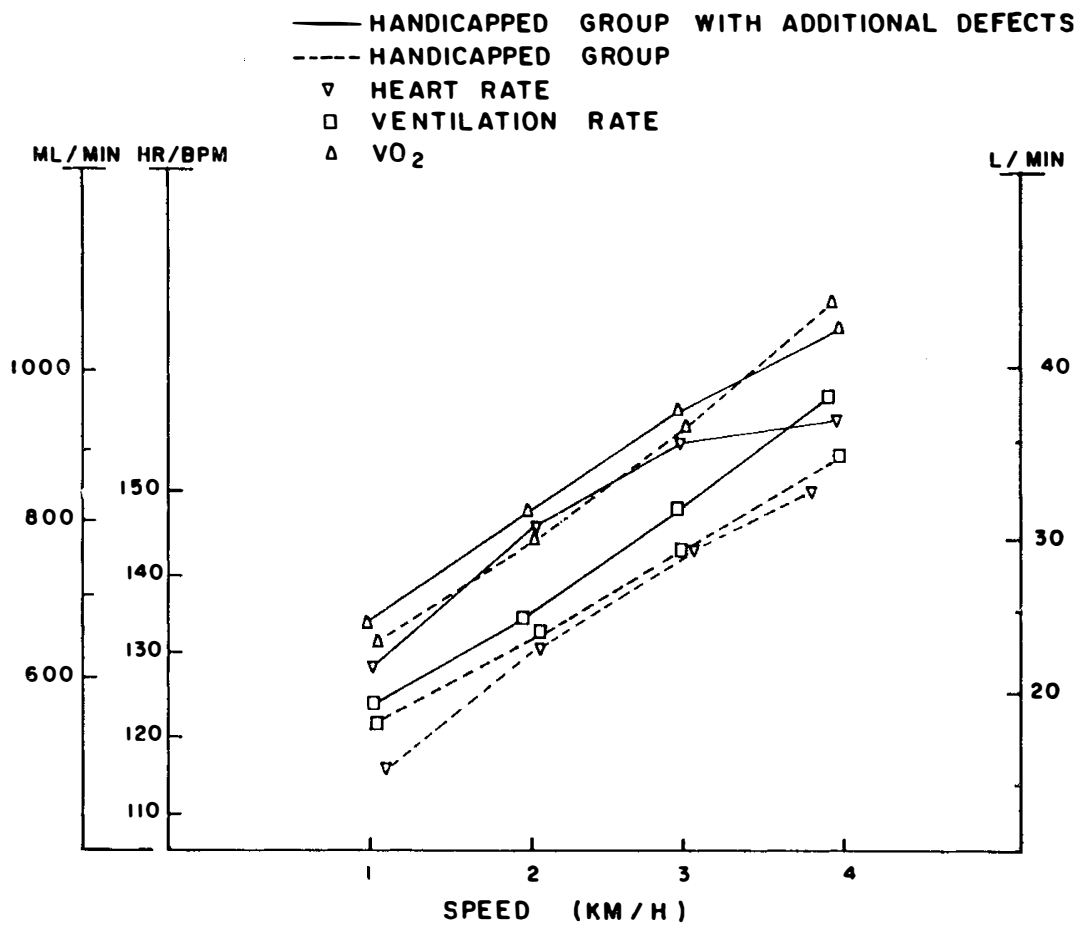

FIG. 3

the subjects (the number was not reported) were lost during the study due to 'muscular fatigue'. The authors concluded that it would be of no value to attempt a training regimen with a wheelchair ergometer because ' $\ldots$ the heart is not exposed to the type of conditioning stimulus which would be necessary to improve its performance capacity'.

Hildebrandt et al. (I970) looked at the energy costs and cardiac responses of propelling a wheelchair at various speeds. They used a similar device and protocol to that of Voigt and Bahn (I969) but looked at various elevations $\left(0^{\circ}, 1^{\circ}, 2^{\circ}\right.$ and $3^{\circ}$ ). The subjects in this case were 29 able-bodied patients ranging in age from 20 to $3 \mathrm{I}$ years. None of the subjects had any prior training in a wheelchair. Mechanical efficiency of wheeling was compared to arm cranking and found to be considerably lower. It was shown that as the workloads increased, to a point, mechanical efficiency increased (see Fig. 4). Heart rate also was shown to increase as the workloads increased; however, no significant differences in heart rates between the wheelchair and arm crank ergometer were found. It was found also that wheelchair driving led quickly to local muscular fatigue. The authors concluded that an arm crank test could be substituted for examining the 'circulatory response to wheelchair propulsion'.

Brattgard, Grimby and Hook (1970) developed a wheelchair ergometer to look specifically at some physiological variables under conditions of exercise-related stress. The ergometer itself consisted of 'wheelchair wheels with driving rims'. The driving wheels were connected to a flywheel from a vonDobeln's bicycle ergometer. The advantage of the wheelchair unit was that it eliminated the source of error caused by 'course instability' while operating a normal wheelchair. The 


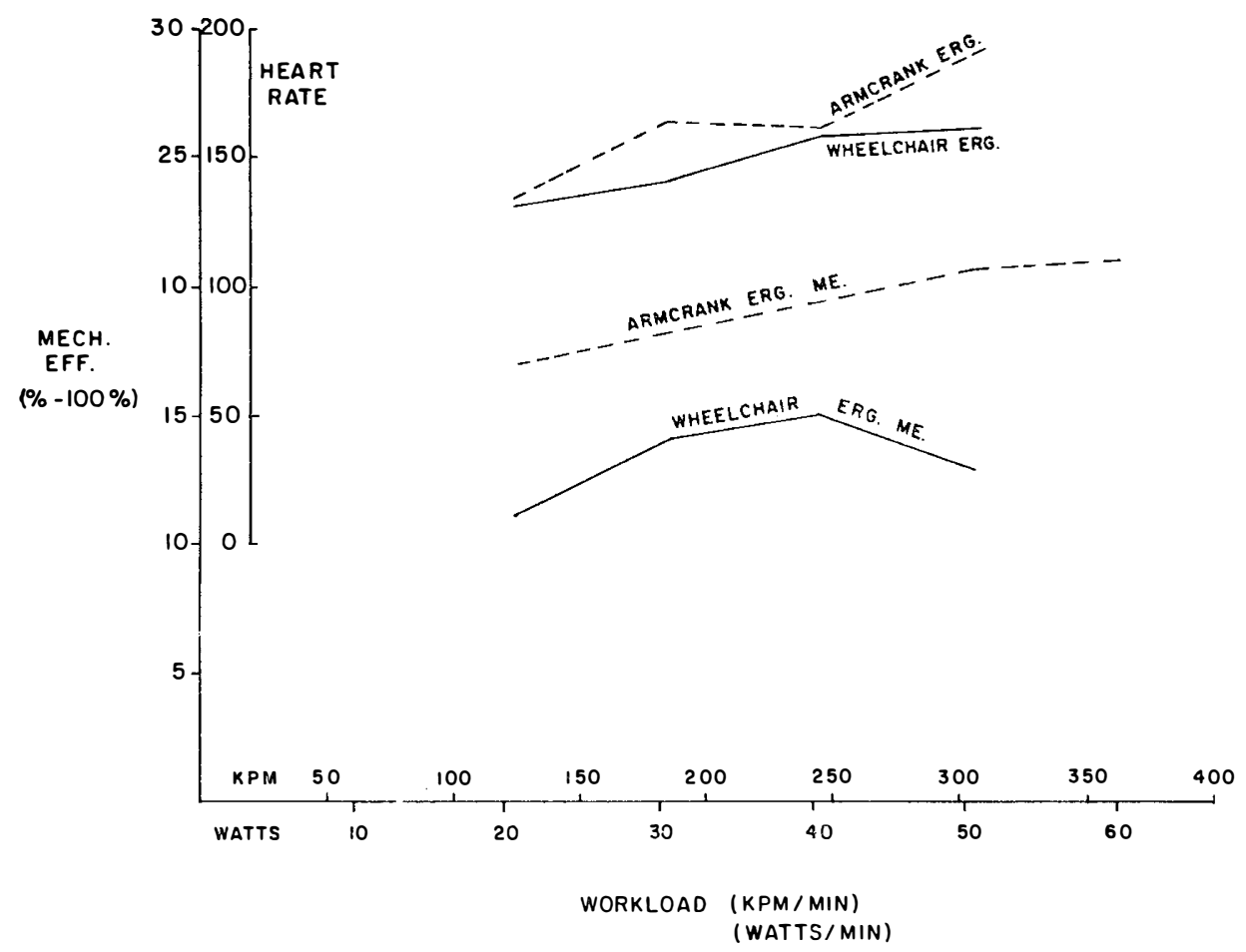

FIG. 4

subjects were 30 able-bodied female physiotherapy students with no prior wheelchair wheeling experience. They were subjected to two workloads $(65 \mathrm{kpm} / \mathrm{min}$ and I Io $\mathrm{kpm} / \mathrm{min}$ ) at each of two different wheel positions (forward and normal) with the wheelchair ergometer. The wheelchair data were then compared to arm crank ergometric work. Workloads on the arm crank ergometer were I 50 and 300 $\mathrm{kpm} / \mathrm{min}$, respectively. No rationale was given for the arm crank workloads. Each of the workloads lasted for 6 minutes. Both workloads with the arm crank ergometer showed mechanical efficiency approximately twice that of the wheelchair loads $(\operatorname{arm}$ crank I $50 \mathrm{kpm} / \mathrm{min}=17.7$ per cent; $300 \mathrm{kpm} / \mathrm{min}=17.5$ per cent; wheelchair $65 \mathrm{kpm} / \mathrm{min}=8 . \mathrm{I}$ per cent; I Io kpm $/ \mathrm{min}=8.9$ per cent) (see Fig. 5). The oxygen uptake increased in all of the higher workloads over that of the lower loads. However, since only two workloads were used, it was difficult to assess the oxygen uptake-workload relationship relative to incremental wheelchair arm work. Heart rate also showed expected increases as workload increased (see Fig. 5).

Brauer (1972) realised the need for better quantified data obtained from wheelchair-confined persons. He noted that one of the major problems was that of accounting for translational inertia that normally occurs with a person freewheeling a wheelchair. He developed an ergometer that would account for the translational momentum of a normal wheelchair. The ergometer was a platform with rollers, but the system included weighted flywheels that would permit simulation of normal wheelchair wheeling. His subjects included 36 young adults. Twenty were ablebodied and I 6 were disabled. The subjects worked at incremental workloads of $0.1,0.2,0.3,0.4$ and $0.5 \mathrm{kcal} / \mathrm{min}(42.7,85.4, \mathrm{I} 28,170.7$ and $213.4 \mathrm{kpm} / \mathrm{min})$. 


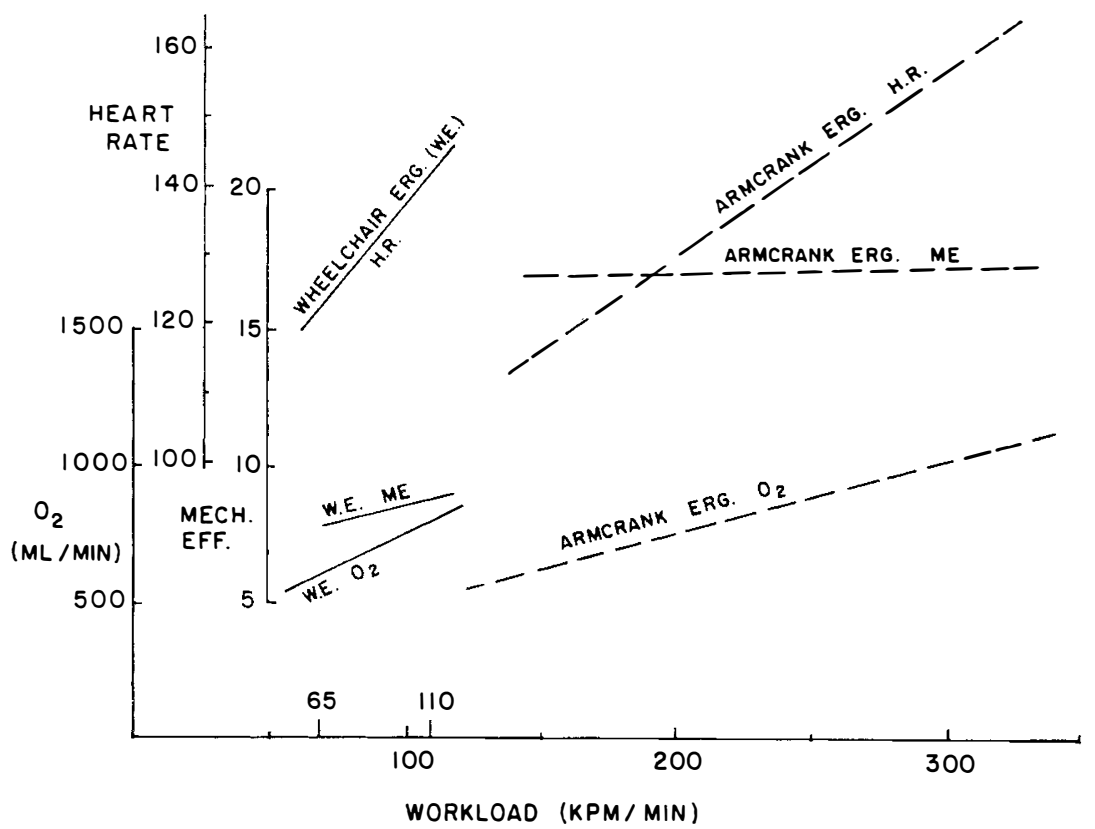

FIG. 5

Each workload was performed at speeds of 2,3 and $4 \mathrm{~km} / \mathrm{hr}$. Net energy expenditure ranged from I kcal $/ \mathrm{min}$ to $2.75 \mathrm{kcal} / \mathrm{min}$ for the disabled and $\mathrm{I} \cdot 25 \mathrm{kcal} / \mathrm{min}$ to $5 \mathrm{kcal} / \mathrm{min}$ for the able-bodied. Heart rate was reported in changes from initial workload. Initial workload heart rates, however, were not reported; therefore, it was difficult to assess his values relative to other publications. Push rates (the number of pushes on the handrims per minute) were found to increase in a linear fashion as the workloads increased. Mechanical efficiency was found to decrease as workloads increased as a function of speed. The results showed that the ablebodied subjects did not perform as well as the disabled. Brauer suggested that this was due to the disabled being accustomed to regular wheeling activity. The two groups were distinctly different. The author concluded that '.. the difference in performance between groups illustrates the benefits which may be accrued through training'. It might be noted that raw data and descriptive statistics were not presented; therefore, only approximations can be reported concerning his results.

Cameron, Ward and Wicks (1977) examined maximal oxygen uptake in male paraplegic athletes. The subjects were 42 male wheelchair athletes competing in the 1976 Olympiad for the physically disabled. Subjects were classified into four groups based on the event in which they were competing; track $=13$, swimming $=$ I I, skill events $=$ IO, strength events $=8$. The subjects competing in vigorous arm events (i.e., swimming and track) produced a mean $\mathrm{VO}_{2 \max }$ in excess of 40 $\mathrm{ml} / \mathrm{kg} \mathrm{min}$. Those athletes participating in strength and skill events produced a mean $\dot{\mathrm{VO}}_{2 \max }$ of 25.6 and $24 \mathrm{ml} / \mathrm{kg}$ min, respectively.

Wicks et al. (I977) studied 72 disabled athletes competing in the 1976 Olympiad for the physically disabled. These data were collected using a progressive symptom limited maximal effort test on a wheelchair ergometer (I977). 
Sixty-one of the subjects were males and I I were females. The men were divided into six international competitive groups (i.e., class I $a, \mathrm{I} b$, II, III, IV and V) and demonstrated a mean $\dot{\mathrm{VO}}_{2 \max }$ of $\mathrm{I} 5.9, \mathrm{I} 5.8,24 \cdot 0,3 \mathrm{I} \cdot \mathrm{I}, 34.5$ and $39.0 \mathrm{ml} / \mathrm{kg} \mathrm{min}$, respectively. The female subjects were divided into two groups (i.e., paraplegic and tetraplegic) and demonstrated a mean $\dot{V O}_{2 \max }$ of 15.5 and $25 . \mathrm{I} \mathrm{ml} / \mathrm{kg} \mathrm{min}$, respectively. When compared with maximal efforts on an arm crank ergometer, the data differed by only 3 per cent.

Wicks et al. (I977b) utilised a multi-stage exercise test with subjects who had spinal cord lesions. The study was designed to compare the exercise responses during arm cranking with those during wheelchair ergometry. The parameters examined were $\mathrm{O}_{2}$ uptake, heart rate, mechanical efficiency and strike rate (the number of strokes per minute on the wheelchair rim). Seven subjects (four men and three women) were used in the study. Five of the subjects had spinal cord lesions and two of the males were able-bodied. The wheelchair ergometer was at a low resistance setting for one test and a high resistance setting for a second test. Increases in wheelchair speeds were required in order to change workloads at each setting. Following the wheelchair ergometer tests, a maximal arm crank test was performed. The results showed that the differences in maximal oxygen uptake, heart rate and ventilation volume between arm cranking and wheelchair ergometry were small and not statistically significant (see Table III). The relationship of strike rate to workload and $\mathrm{O}_{2}$ uptake was linear in each subject.

Glaser et al. (1980) repeated this study with six wheelchair-bound and eight able-bodied subjects, but added the refinement of equivalent workloads for the wheelchair ergometer and arm crank ergometer. He also reported the power output which Wicks had failed to do.

He reported significantly greater performances in maximal physical work capacity (pwc), maximal heart rate and maximal lactic acid ( 36 per cent, 7 per cent and 26 per cent, respectively) with the arm crank ergometer. The correlation data were, however, quite high between the wheelchair ergometer and arm crank ergometer (pwc $-\mathrm{r}=0.86 ; \max$ heart rate $-\mathrm{r}=0.72 ; \max$ lactic acid $-\mathrm{r}=0.52$; oxygen uptake $-\mathrm{r}=0.92$ ). These data implied that cardiorespiratory fitness training could be accomplished via both methods.

Glaser (1978) used 30 able-bodied females in a sub-maximal fitness evaluation test. He repeated the test at a later date and reported that wheelchair ergometry was a reliable method for evaluating circulorespiratory effects of arm work. He also reported (1979) that wheelchair ergometry, compared with bicycle ergometry, shows considerably greater metabolic and cardiopulmonary responses at a given submaximal workload. This is consistent with arm crank vs. bicycle ergometric work (Astrand et al., 1965). These results are attributed to the relatively inefficient biomechanics and relatively small upper body musculature used in propulsion of the wheelchair ergometer relative to bicycle ergometric pedalling. Figure 6 is a summary of Glaser's published $\mathrm{O}_{2}$ data. Other data by Glaser et al. (I980a) have indicated that synchronous wheeling (normal two-handed method) is less efficient than asynchronous wheeling (alternating hand method), and that for a given power output a lower hand rim velocity (power output $=$ handrim velocity-handrim turning force) causes less energy expenditure.

Figure 7 looks at some $\dot{\mathrm{VO}} 2$ data reported by other investigators (included in this review) both able-bodied and wheelchair confined. Glaser's data is somewhat scattered (Fig. 6) but at submaximal ranges they are quite similar. This similarity is encouraging since the various investigators represented used different instrumentation designs. 


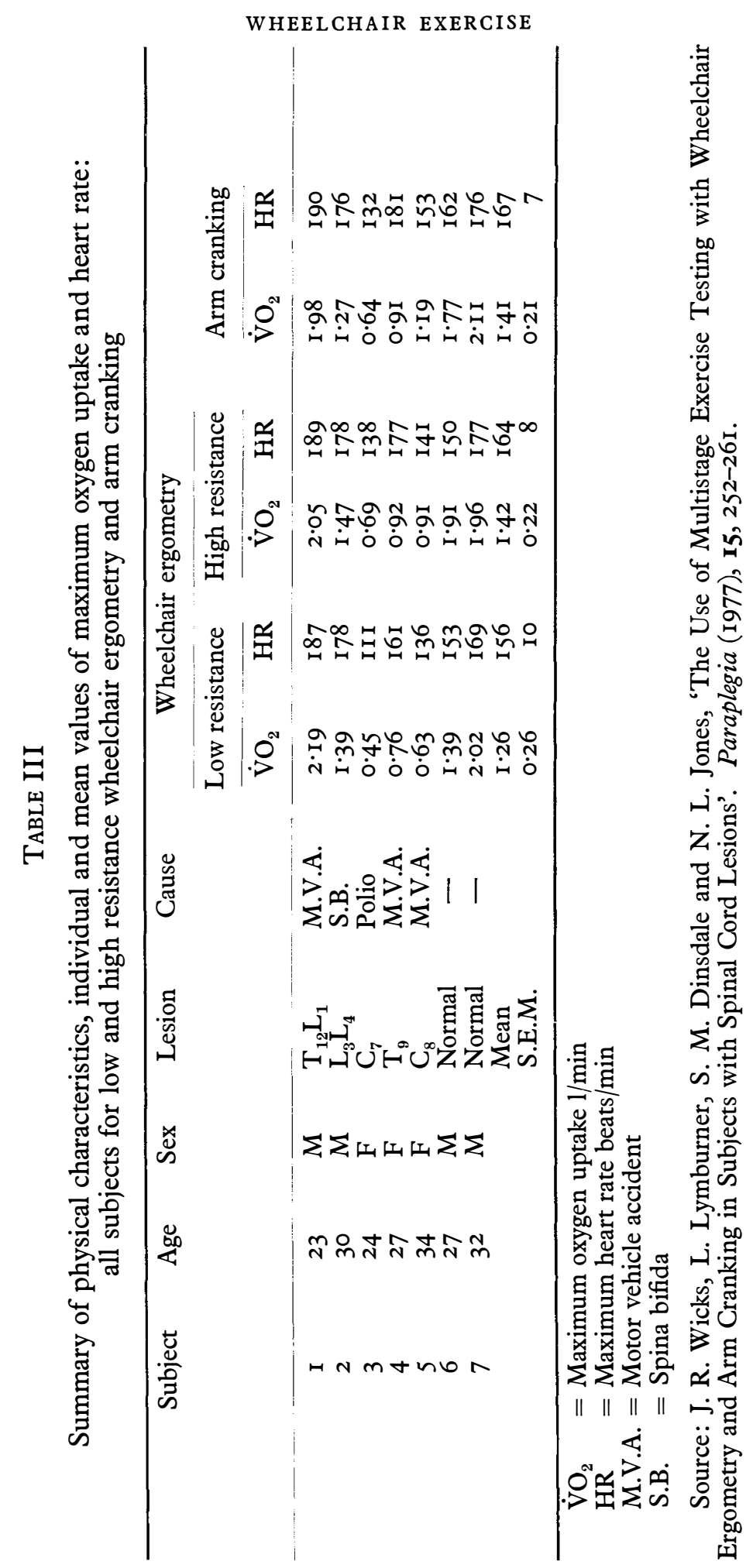




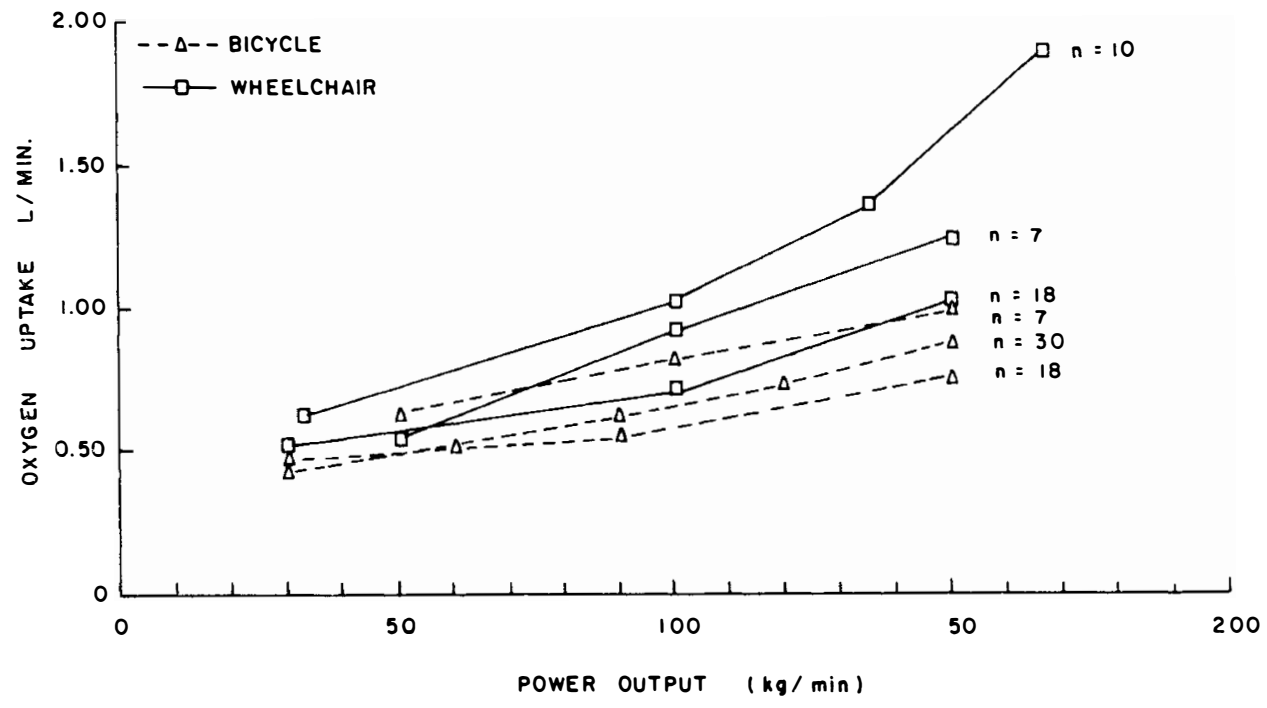

WHEELCHAIR ERGOMETER VS BICYCLE ERGOMETER

FIG. 6

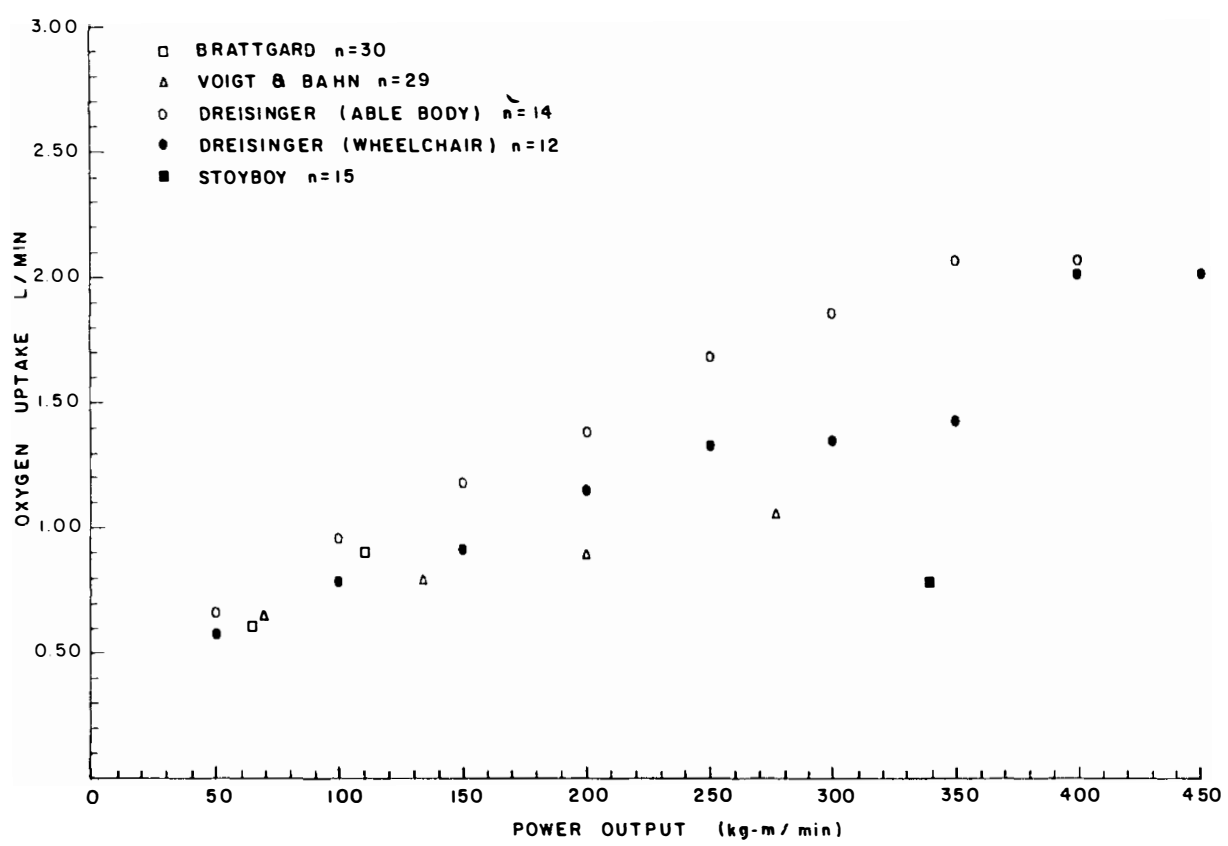

FIG. 7 
A recent case study by Gandee et al. (1980) examined an elite wheelchair marathon racer. The authors reported that an extremely high aerobic capacity was demonstrated. The subject at maximal work output presented a maximal oxygen uptake of $4.21 / \mathrm{min}(64.6 \mathrm{ml} / \mathrm{kg}$-min.), oxygen pulse of $24 \mathrm{ml} /$ beat and a maximal heart of $176 \mathrm{bpm}$. The subject was compared in aerobic capacity to elite Swedish canoeists. To this author's knowledge, these data are by far the highest values reported in the literature for wheelchair ergometric exercise.

Several methods of approaching physiological measurement via wheelchair ergometry have been discussed. Initial work showed that both heart rate and oxygen consumption values increased as workload increased. It was shown that mechanical efficiency increased (up to a point) with workload. Maximal oxygen consumption values were recorded, and it was shown that specificity of training resulted in different maximal oxygen consumption values. Although it is possible that this was a selection factor, it was the first evidence that suggested a potential for circulorespiratory training via wheelchair ergometry.

\section{(c) Wheelchair Training}

The first reported training study relative to wheelchair ergometry was conducted by Engle and Hildebrandt (1973). They were specifically interested in examining the effects of a training programme during a period of clinical rehabilitation. The patients were subjected to a relatively rigorous physiotherapy programme as well as tested on a treadmill-wheelchair ergometric device. The subjects consisted of 13 male paraplegics between the ages of $I_{3}$ and 42 . Wheelchair ergometry exercise was conducted once or twice a week for I 6 weeks. Oxygen consumption values were determined and heart rate was monitored regularly. These data were collected during steady state conditions at treadmill elevations of $0^{\circ}, \mathrm{I}^{\circ}$ and $2^{\circ}$ and at a constant speed of $2 \mathrm{~km} / \mathrm{hr}(\mathrm{I} \cdot 24 \mathrm{mph})$. The results showed a significant training effect during the course of the first I4 weeks. Over the I6-week training programme heart rates at a given speed and elevation decreased an average of $20 \mathrm{bpm}$. This occurred not only at absolute workloads, but at resting conditions as well. No specific data were reported, so it was difficult to compare any of their work to that of other investigators. The authors did note that the training effect could not have been due to the wheelchair work alone but was more directly related to the rigorous physiotherapy treatments that took place in concert with the wheelchair training. The nature of the physiotherapy regimen was not reported.

Glaser et al. (1978) also examined the effect of an interval training programme (ITP) on four able-bodied women in a wheelchair ergometer. Four exercise bouts ( 4 minutes per bout) were performed by the subjects twice a week for 5 weeks. Decreases in submaximal heart rate, respiratory quotient, ventilatory volume and oxygen uptake were reported following the training regimen.

Dreisinger (1978) was interested in the effects of a prescribed exercise regimen on the circulorespiratory state of wheelchair-confined individuals. Twenty-eight men and women ( 12 of whom were confined to manual wheelchairs) were divided into two groups (experimental and control). Each group performed a symptomlimited maximal exercise stress test in a specially constructed wheelchair ergometer. The experimental group trained for 20 minutes, three times a week for 8 weeks, on the stationary wheelchair ergometric device. The control group continued their normal activity for the same 8-week period. The training regimen elicited significant increases $(p<0.05)$ in maximal power output and maximal oxygen uptake values in the experimental vs. control groups. The able-bodied experimental 
group showed significant increases in maximal heart rate, ventilatory volume and lactic acid. It was concluded, therefore, that training with arm work via wheelchair exercise is a practical means of increasing the circulorespiratory fitness levels of wheelchair-confined individuals.

Dalton (1980) examined the effects of wheelchair endurance exercise and vitamin B-I2 supplementation on the depression scale scores of the wheelchair-confined. Thirty volunteers ( 22 male and 8 female) performed a maximal symptom-limited exercise stress test in a wheelchair ergometer and were given the Minnesota Multiphasic Personality Investory (MMPI) Depression (D) scale. The subjects were assigned randomly to three exercise treatment levels: (I) endurance training, (2) matched 'time out' or (3) no exercise treatment. Although the major thrust of this study was not physiological, the endurance training group showed significant increases $(p<0.05)$ in maximal oxygen uptake (following 8 weeks of training-20 minutes - three times a week). Another interesting finding was that the interaction effect of the endurance exercise group taking Vitamin B-I2 supplementation showed significant $(\mathrm{p}<0.025)$ decrease in depression.

The available data indicate that training the circulorespiratory systems of wheelchair-confined individuals is quite possible. Although only a handful of studies have been reported, the current consensus indicates decreases in submaximal heart rate, respiratory quotient, ventilatory volumes and $\mathrm{VO}_{2}$. Maximal exercise training data have indicated increases in power output, $\mathrm{VO}_{2}$, ventilatory volumes and lactic acid. These data are encouraging and hold a bright promise for future research and exercise prescription in wheelchair-confined populations.

This review represents an attempt to consolidate much of the available information concerning the energy costs of wheelchair exercise and the possibility of training wheelchair-confined individuals. The review has been limited to work done by actual freewheeling and wheelchair ergometric development and use.

In summary, $\mathrm{VO}_{2}$ data in freewheeling generally did not agree, however, that the trends were similar. That is to say, as the speeds increased so did the oxygen uptake. Heart rates were reported to be higher for wheelchair exercise versus walking and $\mathrm{VO}_{2}$, both less and similar for the wheelchair versus walking.

The wheelchair ergometric data showed some agreement even though much of the instrumentation utilised was different in its design. It was shown that $\mathrm{VO}_{2}$ and heart rates increased with power output. Mechanical efficiency was also shown to increase with power output up to a point. It now appears that wheelchair ergometric training of the cardiorespiratory system is possible with improvements in maximal and submaximal variables such as power output, $\dot{\mathrm{VO}}_{2}$, heart rate, ventilatory volumes, respiratory quotient and lactic acid.

\section{SUMMARY}

There have been little data available concerning the cardiorespiratory performance of wheelchair-confined populations. The preceding review consolidated much of the available information concerning the energy costs of wheelchair exercise and the trainability of wheelchair-confined populations. In summary, $\mathrm{VO}_{2}$ and heart rate tend to increase linearly with power output. Mechanical efficiency was shown to increase up to a point, then decrease. It appears that training of the cardiorespiratory system is possible with improvement in maximal and submaximal variables such as power output, $\mathrm{VO}_{2}$, heart rate, ventilatory volumes, respiratory quotient and lactic acid levels. This is a fertile area for research. 


\section{RÉSUMÉ}

Il y a très peu d'éléments d'information à l'égard du fonctionnement cardio-respiratoire des gens restraints aux chaises roulantes. Le compte-rendu précédant a consolidé la plupart des renseignements disponibles à l'égard du dépense énergique de l'exercice dans une chaise roulante et la facilité de faire faire l'exercice à ces gens. En somme, $\mathrm{VO}_{2}$ et la fréquence du pouls tendent à augmenter linéairement avec le dépense de puissance. Le rendement mécanique a augmenté jusqu'à un certain point, puis a décliné. Il paraît que la formation du système cardio-respiratoire soit possible avec de l'amélioration des variables maximales et submaximales telles que le rendement de puissance, $\mathrm{VO}_{2}$ la fréquence du pouls, les volumes de respiration, le quotient respiratoire et les niveaux de l'acide lactique. Voici une région de recherche très féconde.

\section{ZUSAMMENFASUNG}

Es waren wenige Angaben vorhanden, die sich mit der Durchführung der Herzatmung von denjenigen Leuten beschäftigen, die an den Rollstuhl gebunden sind. Die vorausgegangene Revision fasste vieles derjenigen verfügbaren Information zusammen, die sich mit den Energiekosten von Rollstuhlübungen und der Möglichkeit der Schulung von Menschen, die an den Rollstuhl gebunden sind, beschäftigen.

Zusammengefasst: $\mathrm{VO}_{2}$ und die Herzfrequenz vermehren sich linear mit der Kraftanstrengung. Es wurde gezeigt, daß der mechanische Kraftaufwand bis zu einem gewissen Punkt zunahm, dann abfiel. Anscheinend ist das Training des Herzatmungssystems möglich mit der Verbesserung von maximalen und beinahe maximalen Variablen, wie Kraftanstrengung, $\mathrm{VO}_{2}$, Herzfrequenz, Herzkammervolumen, Atmungsquotient und Abstufungen der Milchsäure. Das ist ein fruchtbringendes Forschungsgebiet.

Acknowledgment: The authors would like to acknowledge Paraplegia for its permission to use Figure 2 and Table 3 in this work. We would also like to acknowledge Archives of Physical Medicine and Rehabilitation for its permission to use data included in Table I.

\section{REFERENCES}

Astrand, P.-O. Ekbolm, B., Messin, B., Saltin, B. \& Stenberg, J. (i965). Intra-arterial blood pressure during exercise with different muscle groups. F. Appl. Physiol., 20, 253-256.

Astrand, P-O. \& Rodahl, K. (1977). Textbook of Work Physiology. McGraw-Hill, New York.

BALKE, B. \& WARE, R. W. (1959). An experimental study of physical fitness of air force personnel. United States Armed Forces Medical fournal, 10, 675-688.

Bevegard, S., Freyschuss, U. \& Strandell, T. (1966). Circulatory adaptation to arm and leg exercise in supine and sitting position. F. Appl. Physiol., 21, 37-46.

Brattgard, S. O., Grimby, G. \& HoOK, O. (I970). Energy expenditure and heart rate in driving a wheelchair ergometer. Scand. F. Rehab. Med., 2, I43-I48.

BRAUER, R. L. (1972). An ergonomic analysis of wheelchairs. Unpublished doctoral dissertation, University of Illinois, Urbana-Champaign.

Brouha, L. \& Krobath, H. (1967). Continuous recording of cardiac and respiratory functions in normal and handicapped persons. Human Factors, 9, 567-572.

CAMERON, B. J., WARD, G. R. \& WICKS, J. R. (I977). Relationship of type of training to maximum oxygen uptake and upper limb strength in male paraplegic athletes. Med. Sci. Sports, 9, 58 abstract.

Dalton, R. B. (I980). Effects of exercise and vitamin B-I2 supplementation on the depression scale scores of a wheelchair confined population. Unpublished doctoral dissertation, University of Missouri, Columbia, U.S.A.

DREISINGER, T. E. (I 978). Wheelchair ergometry: a training study. Unpublished doctoral dissertation, University of Missouri, Columbia, U.S.A.

ENGLE, P. \& HILDERBRANDT, G. (I 973). Long-term spiro-ergometric studies of paraplegics during the clinical period of rehabilitation. Paraplegia, II, IO5-I IO. 
Fox, E. L., Bartels, R. L., Billings, C. E., Mathews, D. K., Bason, R. \& Webbs, W. M. (I973). Intensity and distance of interval training programs and changes in aerobic power. Med. Sci. Sports, 5, I8-22.

GandeE, R., Winningham, W., Deitchman, R. \& Narraway, A. (I980). The aerobic capacity of an elite wheelchair marathon racer. Med. Sci. Sports, 12 (2), I 42 abstract.

Glaser, R. M., Barr, S. A., Laubach, L. L., Sawka, M. N. and Suryaprasad, A. G. (I980). Relative stresses of wheelchair activity. Human Factors, 22 (2), I77-I8I.

Glaser, R. M., Edwards, M., Barr, S. A. \& Wilson, G. H. (I975). Energy cost and cardiorespiratory response to wheelchair ambulation and walking. Fed. Proc., 34, $46 \mathrm{I}$ abstract.

Glaser, R. M., Foley, D. M., Laubach, L. L., Sawka, M. N. \& Suryaprasad, A. G. (1978-79). Paraplegia, 16, 34I-349.

Glaser, R. M., Laubach, L. L., Foley, D. M., Barr, S. A., Suryaprasad, A. G. \& Burk, R. D. (1978). An interval training program for wheelchair users. Med. Sci. Sports, I0, 54 abstract.

Glaser, R. M., SAWKa, M. N., Brune, M. F. \& Wilde, S. W. (I980). Physiologic responses to maximal effort wheelchair and arm crank ergometry. F. Appl. Physiol., 48 (6), I060-I064.

Glaser, R. M., SAwka, M. N., Brune, M. F. \& Wilde, S. W. (I980a). Applied physiology for wheelchair design. F. Appl. Physiol, 48 (I), 4I-44.

Glaser, R. M., Sawka, M. N., Laubach, L. L. \& Suryaprasad, A. G. (1979). Metabolic and cardiopulmonary responses to wheelchair and bicycle ergometry. F. Appl. Physiol., 46, 1056-1070.

GORDON, E. E. (1952). Energy costs of various physical activities in relation to pulmonary tuberculosis. Archives of Physical Medicine, 33, $201-209$.

Gordon, E. E. (1958). Energy cost of activities in health and disease. Archives of Internal Medicine, A.M.A., 101, 702-713.

Hildebrandt, G., Voigt, E. D., Bahn, D., Berendes, B. \& Kroger, J. (I970). Energy costs of propelling wheelchair at various speeds: cardiac response and effect on steering accuracy. Arch. Phys. Med. Rehab., 51, I3I-136.

Peizer, E., Wright, D. \& Freiberger, H. (I964). Bioengineering methods of wheelchair evaluation. Bulletin of Prosthetics Research, 10-1, 77-100.

Stoboy, H., Rich, B. W. \& LEE, M. (I97I). Workload and energy expenditure during wheelchair propelling. Paraplegia, 8, 223-230.

VoIGT, E. D. \& BAHN, D. (I969). Metabolism and pulse rate in physically handicapped when propelling a wheelchair up an incline. Scand. F. Rehab. Med., I, IOI-IO6.

Wicks, J. R., Head, E., Oldridge, M. B., Cameron, B. \& Jones, N. L. (I977). Maximum oxygen uptake of wheelchair athletes competing at the 1976 Olympiad for the physically disabled. Med. Sci. Sports, 9, 58 abstract.

Wicks, J. R., Lumburner, L., Dinsdale, S. M. \& Jones, N. L. (1977). The use of multistage exercise testing with wheelchair ergometry and arm cranking in subjects with spinal cord lesions. Paraplegia, 15, 252-26I.

Wolfe, G. A., WATERS, R. \& HISLOP, H. J. (I97I). Influence of floor surface on the energy cost of wheelchair propulsion. Physical Therapy, 57, 1022-1027. 